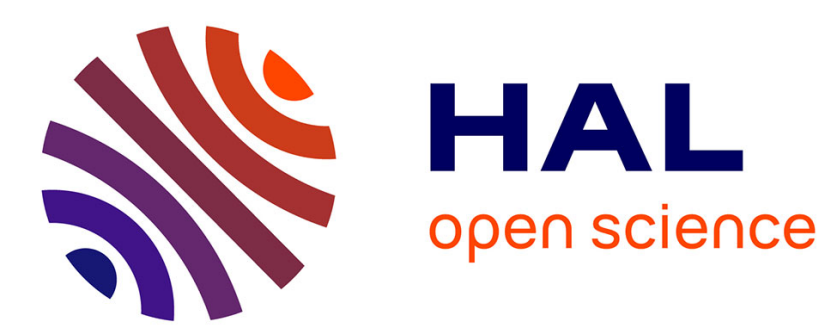

\title{
Le paradoxe de la patrimonialisation littéraire en contexte camerounais (1950 à 1980)
}

Murielle Sandra Tiako djomatchoua

\section{To cite this version:}

Murielle Sandra Tiako djomatchoua. Le paradoxe de la patrimonialisation littéraire en contexte camerounais (1950 à 1980). Culture et Musées, 2021, pp.307 - 311. 10.4000/culturemusees.7392 . hal-03471630

\section{HAL Id: hal-03471630 \\ https://hal.science/hal-03471630}

Submitted on 8 Dec 2021

HAL is a multi-disciplinary open access archive for the deposit and dissemination of scientific research documents, whether they are published or not. The documents may come from teaching and research institutions in France or abroad, or from public or private research centers.
L'archive ouverte pluridisciplinaire HAL, est destinée au dépôt et à la diffusion de documents scientifiques de niveau recherche, publiés ou non, émanant des établissements d'enseignement et de recherche français ou étrangers, des laboratoires publics ou privés. 


\title{
OpenEdition
}

Journals

\section{Culture \& Musées}

Muséologie et recherches sur la culture

$38 \mid 2021$

Patrimonialisations de la littérature

Études \& notes de recherche

\section{Le paradoxe de la patrimonialisation littéraire en contexte camerounais (1950 à 1980)}

\author{
Murielle Sandra Tiako DJomatchoua
}

p. $307-311$

https://doi.org/10.4000/culturemusees.7392

\section{Entrées d'index}

Rubriques: Notes de recherche

\section{Texte intégral}

Cette note de recherche en cours examine les tensions entre les instances politiques et les institutions littéraires à l'origine du processus de patrimonialisation de la littérature camerounaise des années 1950 à 1980. Par patrimonialisation du fait littéraire au Cameroun, on entend les modes de formation des classiques étudiés sous deux points de vue : d'une part la consécration des œuvres et leur pérennisation dans le paysage littéraire, et d'autre part les imaginaires autour des auteurs que se construisent le politique et les publics. Quel est le rôle de la censure et quelle est la place de la mémoire collective dans le processus de patrimonialisation ? Mon objectif est d'analyser le paradoxe qui résulte des tentatives politiques de patrimonialisation de la littérature à partir d'une étude de cas. Ce paradoxe jaillit du croisement entre consécration et censure, tant les véritables classiques camerounais que le monde littéraire et la mémoire collective nationale retiennent aujourd'hui des années 1950 à 1980 au Cameroun sont des auteurs qui ont été frappés sévèrement par la censure, à l'instar de Mongo Beti. 

par rapport au contrôle politique et politisé de la parole et du discours qui circulent au sein de l'espace public. L'émergence de la première génération d'écrivains révolutionnaires, " avec pour chefs de file Mongo Beti et Ferdinand Oyono » (Ackad, $1985: 7-8$ ), crée le premier choc entre le politique et le littéraire par le fait que ces auteurs produisaient des discours anticonformistes, contestataires et iconoclastes, contrairement à la tendance panégyrique de leurs prédécesseurs. Une rivalité entre l'autorité politique et l'institution littéraire s'active dès que la question de la conquête et du contrôle de l'espace public entre en jeu. C'est dans ce contexte de rapports tendus que la question de la patrimonialisation de la littérature m’intéresse.

\section{Les discours littéraires et les discours politiques face aux miroirs coloniaux}

La fin de la Deuxième Guerre mondiale en 1945, la création du premier parti nationaliste, l'Union des populations camerounaises (UPC), par Ruben Um Nyobe le 10 avril 1948 (Eyinga, 1991 ; Richard, 2000), et la montée des revendications d'autodétermination face au joug colonial (Mbembe, 1985, 1996 ; Deltombe et al., 2011) constituent trois événements qui préparent l'effervescence des années cinquante au Cameroun. "Années de braise ${ }^{1}$ » en littérature et temps forts des mouvements nationalistes, ces années voient la parution des premiers textes anticoloniaux et dissidents (Philombe, 1977 ; Kayo, 1978 ; Konka, 1983). L'engagement d'auteurs tels que Mongo Beti et Ferdinand Oyono introduit la littérature dans le champ du militantisme pour les indépendances effectives du Cameroun, alors territoire sous le joug des administrations coloniales française et britannique. Cette littérature engagée défie l'autorité coloniale en dislocation, pose les jalons d'une conscience politique chez les peuples colonisés, œuvre pour l'éveil et le contrôle de l'espace public camerounais, encore à l'état embryonnaire, et milite pour l'émancipation du pays (Kemedjio, 2006 ; Aït-Aarab, 2013).

4 La dénonciation de la mainmise coloniale sur l'État embryonnaire camerounais au lendemain des indépendances sème la polémique sur la légitimité du processus d'accession au pouvoir de ses dirigeants. Ces querelles s'exacerbent dès lors que l'État impose à la mémoire collective nationale un discours officiel et unilatéral falsifié car œuvrant à aseptiser les figures emblématiques et pionnières des combats indépendantistes telles que Ruben Um Nyobé et ses compagnons de lutte, pour la plupart assassinés entre 1958 et 1971 (Onana Mfege, 2005 : 263 ; Mbembe, 1986 : 3740 ; Abomo, $2017: 81-85$ ).

5 En tentant de contrôler tyranniquement l'espace public, le projet étatique d'éradication de la dissidence et de l'opposition devient le reflet hyperbolique de l'oppression coloniale. Le conflit de légitimité entre l'État et les institutions littéraires en résulte donc logiquement dès lors que des textes sur la communication sociale sont promulgués, notamment l'ordonnance $\mathrm{n}^{\circ}$ 62-OF-du 12 mars 1962 sur la répression de la subversion et les lois de 1966 sur la subversion. La création et l'imposition d'un parti unique (Bayart, 1978) confirment la reproduction et la prolongation des miroirs coloniaux après les effervescences de l'indépendance et les promesses du Cameroun postcolonial. Cet engrenage, propice à la surveillance et à l'arbitraire, influence et oppresse l'institution littéraire, de même que la connivence de l'exécutif avec les autres armes de communication de l'État dissuade et asphyxie l'émergence de tout discours ou idéologie contraire à l'ordre politique dominant et totalitaire.

\section{Des consécrations sous la gâchette de la censure}


La période de construction nationale (1960-1980) et d'effervescence éditoriale marquée par la multiplication des moyens de production du livre (Fandio, $2012: 32$ ), l'activisme pédagogique de l'Association des poètes et écrivains du Cameroun (APEC) ainsi que l'impact de la revue culturelle Abbia et des Éditions CLÉ sur la diffusion des textes littéraires (ibid. ; Thierry, 2015 : 214-223) sont autant d'exemples de l'investissement financier et matériel du politique dans le champ littéraire. Ainsi, la consécration en littérature devient un mode de patrimonialisation par lequel des textes et des auteurs accèdent à une reconnaissance et circulent au sein de la communauté des lecteurs et des structures sociales. Les auteurs ainsi consacrés par le politique deviennent des modèles, des références, participant à la validation de l'ordre et de l'idéologie politique auxquels ils sont asservis. C'est la raison pour laquelle, lorsque l'État camerounais subventionne des maisons d'édition, octroie des récompenses autant politiques (postes à responsabilités ou titres honorifiques donnant droit à des privilèges) que littéraires aux auteurs et mobilise les médias (Fandio, 2006), il met en place une conscience patrimoniale du fait littéraire en conditionnant à la fois les lecteurs et les autres membres de la société qui sont ciblés par la propagande des médias à la solde du gouvernement. Cependant, la réalité de cette canonisation « politique » repose sur un "procès idéologique » qui vise « à la validation d'un type d'écriture "omnibus", Mission terminée ; en même temps qu'elle disqualifie une autre, l'écriture "engagée", Le Pauvre Christ de Bomba » (ibid. : 41)². Ainsi, " On pourrait même penser que certains visent véritablement à réduire l'influence et l'aura des écrivains comme Mongo Beti dont les premiers textes sont unanimement salués autant par la critique que par les nationalistes et les progressistes africains » (ibid.).

Dans le contexte postcolonial camerounais, la consécration par l'État repose principalement sur l'accès aux financements et aux distinctions politiques. Pendant que l'État « crée et attribue des prix littéraires, finance, même symboliquement, les activités de l'association des écrivains en même temps qu'il prend en charge l'organisation des assises nationales de l'APEC », il interdit de circulation sur le territoire national des textes jugés subversifs et menace de prison et/ou de mort leurs auteurs (Fandio, 2006 : 26-27). Par ailleurs, cette censure se déconnecte aussi du fait littéraire et instrumentalise des appareils de l'État pour écraser l'écrivain, comme c'est le cas pour René Philombe, " arrêté, gardé à vue et traîné devant les tribunaux civils et militaires pour ses activités littéraires "subversives" » afin de le contraindre à l'exil, à l'instar de Mongo Beti, et pour soumettre son entourage à des pratiques d'intimidation et de tortures physiques et psychologiques » (ibid.). Pour contraindre les maisons d'édition à adhérer à l'ordre du discours politique, le politique va promulguer des lois sur la subversion dont l'implémentation militarisée sera le fait d'une police judiciaire œuvrant pour le musèlement de la dissidence. Par conséquent, la censure qui menace et soumet les maisons d'édition se confirme par les taux de tirage. En effet, durant cette période, « trois textes littéraires camerounais seulement [sont] publiés, dont deux éditeurs sur place et un à l'étranger » (ibid. : 70).

La conscience collective nationale de cet état des choses crée une "psychose » chez les individus dont les lectures sont contrôlées par l'État et dont l'accès au livre est assez limité compte tenu de la petitesse des revenus, de la faible implantation de l'habitus de lecture, de la crise économique, de la dévaluation du franc et de la primauté des impératifs de subsistance sur les besoins de culture et de formation (ibid. : 14 ; Fandio, 2012 ; Thierry, 2015). Cependant, une patrimonialisation alternative à celle imposée et pilotée par l'État prend corps au sein de la conscience collective nationale et internationale grâce aux travaux et aux recherches universitaires sur les auteurs révolutionnaires camerounais, à la création et à l'octroi des consécrations allogènes, tous instruments de la fabrique des classiques camerounais.

\section{Le paradoxe de la patrimonialisation au Cameroun}


Le phénomène commun de l'érosion des textes par le temps ne rend pas entièrement compte du paradoxe de la patrimonialisation au Cameroun, car les changements de régime politique n'ont pas amélioré la condition des écrivains ni la situation des institutions de production de biens symboliques au Cameroun. Au contraire, tout va de mal en pis en ce qui concerne le paysage littéraire national. Cependant, l'internationalisation de la littérature camerounaise offre des alternatives de contournement de la censure et, par ricochet, des armes de résistance littéraire politisées et politisables. La possibilité de publier en France libère inévitablement la parole et donne aux textes et aux auteurs dissidents une plus grande exposition (Ducournau, 2017 : 13). Paradoxalement, les textes d'auteurs vulgarisés par l'État n'ont ni survécu après la chute du régime du président Ahmadou Ahidjo, ni été conservés dans la mémoire nationale car désincarnés et déconnectés des réalités et des préoccupations des populations (Fandio, 2006).

D'autre part, l'appartenance d'écrivains camerounais à une communauté d'auteurs ${ }^{3}$ et de mouvements littéraires ${ }^{4}$, les recherches académiques au sein des universités occidentales et américaines, et les travaux des critiques littéraires ont propulsé les auteurs nationaux honnis aux panthéons de la littérature camerounaise d'une part, et africaine d'autre part. À travers les nominations ou les distinctions aux prix internationaux, l'audience des auteurs nationaux dissidents s'est accrue, s'est consolidée et a trouvé dans la conscience nationale des lecteurs opprimés et étouffés par les pressions de régimes tyranniques une base solide. C'est tout ceci qui a contribué à transformer plusieurs textes interdits de parution et de circulation des années 1950 à 1980 en d'incontournables classiques aujourd'hui.

\section{Bibliographie}

Ackad (Josette). 1985. Le Roman camerounais et la critique. Paris : Silex éditions (A3).

Abomo (Pierre). 2017. « Le destin politique de la mémoire du nationalisme camerounais : entre réhabilitation et rejet ». Cahiers Mémoire et Politique [en ligne], 4, " Approche comparée des politiques mémorielles », p. 81-98 : https://popups.uliege.be/2295-0311/index.php?id=181 [consulté le 6 juillet 2021].

DOI : 10.25518/2295-0311.181

Aït-Aarab (Mohamed). 2013. «Chapitre 2. L'engagement littéraire sur les chemins de l'écriture oblique », p. 279-302 in Mongo Beti. Un écrivain engagé / sous la direction de Mohamed AïtAarab. Paris : Karthala.

Bayart (Jean-François). 1978. « Régime de parti unique et systèmes d'inégalité et de domination au Cameroun : esquisse ». Cahiers d'études africaines, 69-70, p. 5-35.

DOI : 10.3406/cea.1978.2392

Deltombe (Thomas), Domergue (Manuel) \& Tatsitsa (Jacob). 2011. Kamerun! Une guerre cachée aux origines de la Françafrique (1948-1971). Paris : La Découverte.

Ducournau (Claire). 2017. La Fabrique des classiques africains. Écrivains d'Afrique subsaharienne francophone. Paris : CNRS éditions (Arts et essais littéraires).

Eyinga (Abel). 1991. L'U.P.C., une révolution manquée ? Paris, Dakar : Chaka éditions.

Fandio (Pierre). 2006. La Littérature camerounaise dans le champ social. Grandeurs, misères et défis. Paris : L’Harmattan (Études africaines).

Fandio (Pierre). 2012. Les Lieux incertains du champ littéraire camerounais contemporain. Paris : L'Harmattan (Cameroun).

Kayo (Patrice). 1978. Panorama de la littérature camerounaise. Yaoundé : Librairie panafricaine.

Kemedjio (Cilas). 2006. "Traversées francophones : littérature engagée, quête de l'oralité et création romanesque ». Tangence, 82, « Savoirs et poétique du roman francophone », p. 15-39.

Konka (Romain). 1983. Histoire de la littérature camerounaise. Paris : R. Konka.

Mbembe (Achille). 1985. «La palabre de l'indépendance : les ordres du discours nationaliste au Cameroun (1948-1958) ». Revue française de science politique, 35(3), p. 459-487.

Mbembe (Achille). 1986. « Pouvoir des morts et langage des vivants. Les errances de la mémoire nationaliste au Cameroun ». Politique africaine, 22, p. 37-72.

Mbembe (Achille). 1996. La Naissance du maquis dans le Sud-Cameroun (1920-1960). Paris : Karthala. 
Ngomayé (Esther Solange). 2015. « La ronde des poètes ou la lutte de la multitude pour l'autonomie du champ littéraire camerounais ». Cahiers d'histoire, 33(1-2), p. 37-56.

DOI : 10.7202/1042874ar

Onana Mfege (André-Hubert). 2005. « L’armée de libération nationale kamerunaise et sa stratégie révolutionnaire, 1959-1970 ». Outre-Mers, revue d'histoire, 348-349, p. 255-269.

Philombe (René). 1977. Le Livre camerounais et ses auteurs : Une contribution littéraire du Cameroun avec notice bio-bibliographique. Yaoundé : Éditions Semences africaines.

Richard (Joseph). 2000. Le Mouvement nationaliste au Cameroun : Les origines sociales de l'UPC. Paris : Karthala.

Thierry (Raphaël). 2015. Le Marché du livre africain et ses dynamiques littéraires. Le cas du Cameroun. Pessac : Presses universitaires de Bordeaux (Littérature des Afriques).

\section{Notes}

1 Année de montée en puissance des premiers textes qui critiquent sans détours le pouvoir.

2 De ces deux romans de Mongo Beti, Mission terminée (1957) reçut un bon accueil, alors que Le Pauvre Christ de Bomba (1956), plus critique, fut censuré. Quant au "type d'écriture "omnibus" ", il fait référence à Pierre Bourdieu et ses "faits omnibus " présentés à la télévision lors des informations, et « qui font le consensus, qui intéressent tout le monde mais sur un mode tel qu'ils ne touchent à rien d'important » (Sur la télévision, 1996, Paris, Raisons d'agir, p. 16).

3 On peut citer, entre autres exemples : l'Association des poètes et écrivains camerounais (APEC) ; l'association Les Amis de la littérature ; Auteurs et illustrateurs du livre pour enfants (AILE) ; la compagnie Agbetsi International ; l'Association des professionnels du théâtre du Cameroun (Apthec) ; l'Association de lutte pour l'éducation par la poésie (Lupeppo international) ; Les Cahiers de l'estuaire ; le Cercle des amis de la littérature, écrivains et poètes inconnus (Calepi) ; l'Académie des urgentistes bénévoles de l'éducation (AUBE).

4 On peut mentionner la Nouvelle Littérature camerounaise (Nolica) qui, « elle, est une association, un mouvement et une théorie littéraires au Cameroun » (Ngomayé, 2015 : 50).

\section{Pour citer cet article}

Référence papier

Murielle Sandra Tiako Djomatchoua, « Le paradoxe de la patrimonialisation littéraire en contexte camerounais (1950 à 1980) », Culture \& Musées, 38 | 2021, 307-311.

Référence électronique

Murielle Sandra Tiako Djomatchoua, "Le paradoxe de la patrimonialisation littéraire en contexte camerounais (1950 à 1980) », Culture \& Musées [En ligne], 38 | 2021, mis en ligne le 10

novembre 2021, consulté le 08 décembre 2021. URL :

http://journals.openedition.org/culturemusees/7392; DOI :

https://doi.org/10.4000/culturemusees.7392

\section{Auteur}

\section{Murielle Sandra Tiako Djomatchoua}

Princeton University

Murielle Sandra Tiako Djomatchoua est étudiante en doctorat de littérature française et

francophone à Princeton University « États-Unis ». Elle s'intéresse aux rapports que la littérature francophone entretient avec la sociologie, la politique, l'anthropologie, le folklore et les religions. Elle a à son actif les publications suivantes : « Espace, mémoire, identité : pour un féminisme existentialiste dans Le ventre de l'Atlantique et La préférence nationale de Fatou Diome », dans Au carrefour des mondes: narratifs en français de femmes migrantes du XXIe siècle (ouvrage collectif édité par Kirsten von Hagen, Marina Ortrud M. Hertrampf, Hanna Nohe. München : AVM, 2021, p. 165-183), « Du jeu des perceptions autour de l'objet à la scénographie de la violence du sacré dans Les Noces sacrées de Seydou Badian " (Travaux de Littérature, $\mathrm{n}^{\circ} 33$, "Poétique de l'objet », 2021) ; "Raconter les crises en postcolonie : nouvelles voix ou voies nouvelles dans Temps de chien de Patrice Nganang " (dans l'ouvrage collectif édité par Simona Jia, Sergiu Micoiu et Modibo Diarra, Raconter les politiques conflictuelles en Afrique. Regards croisés, Paris, Éditions du Cerf, coll. " Patrimoines », 2021, p. 223-245) ; « Briser les frontières : l'écriture d'une surréalité spatiale dans Les Yeux de ma chèvre. Sur les pas des maîtres de la nuit en pays douala (Cameroun), d’Éric de Rosny » (Éthiopiques, $\mathrm{n}^{\circ}$ 104-105, « Sociétés, environnement et autres textes », 2020, p. 44-56) ; " Crimes et châtiments surnaturels chez Djibi Thiam et Seydou Badian : une lecture de Ma sœur la panthère et Les Noces sacrées » (African Journal of Literature and Humanities, vol. 2, $\mathrm{n}^{\circ} 1,2020$, p. 169-179).

Courriel : mt2200[at]princeton.edu 
Droits d'auteur

Culture \& Musées 